\title{
Cerebral air embolism after central venous catheter removal: a case report and literature review
}

\begin{abstract}
Objective: To explore the clinical manifestations, managements and prognosis of cerebral air embolism after central venous catheter removal.

Methods: A 51-year-old female had thoracic sympathecotomy for her Raynaud's disease under video assisted thoracoscopic surgery. She was confirmed having congenital atrial septal malformation. The surgical procedures were uneventfully. She was suddenly onset of shortness of breathing, consciousness loss and convulsion after the right internal jugular venous catheter removal. The CT scan showed the air embolism on the right frontal lobes of the brain. Her left extremities were paralysis. She walked on hers own with her left hand weakness by multidiscipline therapy including hyperbaric oxygen therapy after five weeks. Five relevant case reports (from Jan 2000 to Jun 2013) were found in PubMed, EMBASE and Google Scholar.
\end{abstract}

Results: All of six cases had CT or MRI signs of cerebral air embolism. The air emboli entered into artery system from venous system through potential right to left shunt in four cases after the central venous catheters pulled out. Those patients who were diagnosed as paradoxical cerebral air embolism manifested hemiplegic. Two cases showed the air emboli in sinus cavernosus and the cortical veins which resulted in cerebral venous air embolism and cerebral edema, in which the symptoms disappeared within few hours.

Conclusion: It is important to prevent cerebral air embolism when removing the central venous catheter. The approaches are as follows: asking patient in supine position, instructing patient breath holding, applying Vaseline gauzes or antibiotic ointments and covering the exit site with airtight tapes.

Keywords: Cerebral air embolism, Central venous catheter remova, Paradoxical cerebral air embolism; Cerebral venous air embolism; Hemiplegic, Hyperbaric oxygen therapy
Volume I Issue 2 - 2014

Youming zong

Department of Critical Care Medicine, Jiaxing First Hospital, China

Correspondence: Youming Zong, Jiaxing First Hospital, Jiaxing Zhonghuan Nanlu 1882, Zhejiang Province, China, Tel 86-573825I-9099, Fax 86-573-8208-3006, Email jxicu@।63.com

Received: May 23, 2014 | Published: June 09, 2014
Abbreviations: RIJV; Right Internal Jugular Vein; LSV; Left Subclavian Vein; PFO, Patent Foramen Ovale, PCAE, Paradoxical Cerebral Air Embolism; CVAE; Cerebral Venous Air Embolism

\section{Introduction}

Both internal jugular vein or subclavian vein puncture and central venous catheter insertion are commonly used in patients for different purposes, such as hemodynamic monitoring, administration of medications, parenteral nutrition, hemodialysis, transvenous pacing, poor peripheral access and so on. The complications of the central venous catheter can occur at any time when the catheter is inserted, in use, or even at the time of catheter removal. These complications include hemorrhage, pneumothorax, embolism and infection., Among them, air embolism is a potentially catastrophic, usually threats to life. Once cerebral air embolism occurs, it usually takes a long time for rehabilitation and affects the patient daily life because hemiplegia and extremities disability resulted from cerebral ischemia infarction or edema. We describe a case of cerebral air embolism after internal jugular central venous catheter removal and search relevant literatures for review.

\section{Case presentation}

A 51-year-old female was diagnosed as Raynaud's disease with her hands cold and pain for 7 years. She had undergone thoracic sympathetic nerve radiofrequency thermal ablation 6 months ago but relapsed. She was admitted for thoracic sympathecotomy under video assisted thoracoscopic surgery. Physical examinations including oxygen saturations, heart rates, respiration rates and blood pressure were in the normal range. Systolic murmur could be heard on the left of the sternum. Extremities and neurological examinations were normal. The echocardiogram illustrated the atrial septal malformation and pulmonary hypertension. The procedures of right internal jugular vein puncture and catheterization (ARROW single-lumen catheter), anesthesia and surgery were uneventfully. Her hands turned to warm after surgery.

Five days later, the internal jugular venous catheter was planned to remove. She was instructed in supine position and holding breath when the internal jugular vein catheter was pulled out. The exit site was pressed with gauze for 1 minute, and then fixed by the tapes. She was asked to keep in supine. She was suddenly onset of shortness of breathing, consciousness loss and convulsion after 3 minutes. Given $100 \%$ oxygen by non-rebreathing mask ventilation, then the endotracheal intubation was implementing. Her blood pressure was $158 / 108 \mathrm{mmHg}$; pulse rates were 119 beats per minute with regular and sinus rhythm. Pupils were of normal size and reacting symmetrically. Emergency head CT scans showed the signs of cerebral air embolism on the right frontal lobes of the brain (Figure 1). She was diagnosed as paradoxical cerebral air embolism and transferred to ICU. She regained consciousness after 3 hours and the endotracheal tube was removed. She presented hoarseness and paralysis on the left extremities with grade zero power. The right lower extremity was grade four powers. She was received the hyperbaric oxygen therapy twice a day for the first week. She was shifted to a stroke rehabilitation facility and continued hyperbaric oxygen therapy once a day. After 
two weeks rehabilitation, the left and the right lower extremities were grade four powers, her left upper extremity remained with grade zero power. Four weeks later, her hoarseness disappeared. Both of her lower extremities were grade five powers. She could walk independently after five weeks. Her left upper extremity was grade four powers. We searched in PubMed, EMBASE and Google Scholar for relevant articles from Jan 2000 to Jun 2013. Key word included cerebral air embolism, paradoxical cerebral air embolism, retrograde cerebral air embolism, central venous catheter removal. Five similar case reports were found (Table 1).

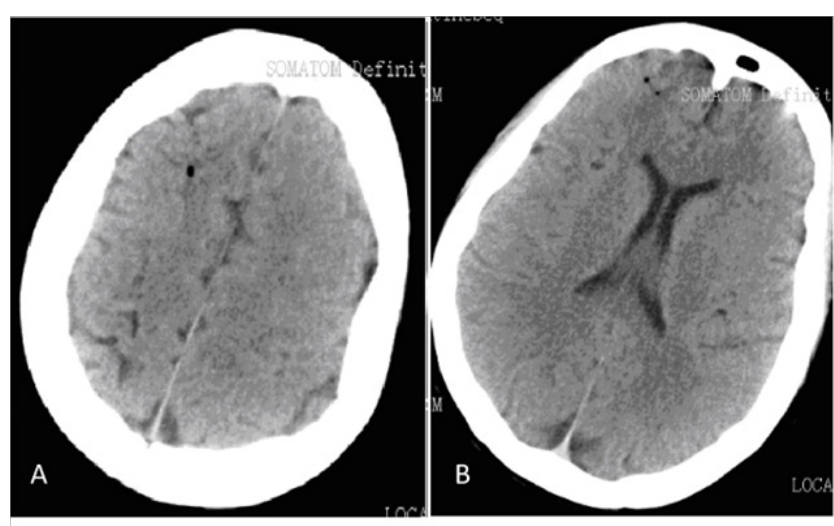

Figure I Head CT images reveal air bubble in right frontal lobe.

\section{Discussion}

The central venous catheterization is widely used in clinical practice. The complications include hemorrhage, infection, pneumothorax and embolism etc. However, it is limited to the sporadic case reports about cerebral air embolism following the central venous catheter removal. When it occurs, the patient is often life-threatening ${ }^{8}$ First of all, the patient should be in supine or at least half-lying position. The exit site is pressed by gauze immediately for 5 minutes when the catheter pulls out, and then fixed by tapes. ${ }^{1-9}$ It is rare that the cerebral air embolism occurs after the central venous catheter removal. A persistent residual catheter track might be presented which allowing air to enter into the vascular even if the exit site taped. ${ }^{5}$ The outside air seems to be more likely entered into if the patient experiences a reduction in the central venous pressure, such as upright position or deep inspiration after removing of the central venous catheter. ${ }^{10}$ The patient manifests dyspnea, loss of consciousness, or seizures. Most of them have no circulatory collapse.

Cerebral air embolism followed by central venous catheter removal is characterized by two mechanisms. One is the result of the air emboli passing through the potential right to left shunts. Such shunts include congenital atrial septal malformation, patent foramen ovale, etc. It is reported that the rate of patent foramen ovale is about $35 \% .{ }^{11}$ Air emboli from the venous system enter into the arterial system directly and result in cerebral arterial air embolism. It is also known as paradoxical cerebral air embolism. ${ }^{12}$ Another is the air emboli which retrograde into cerebral venous system from internal jugular vein when the patient is on sitting position. Accordingly, the air emboli could be found in the cavernous sinus or intracranial venous system. ${ }^{13}$ Paradoxical cerebral air embolism results in the brain cortex or focal ischemia infarction and central nerve system dysfunction. Cerebral venous air embolism results in cerebral venous drainage barriers that result in cerebral edema. In our case the air emboli enter into the left atrium from the right atrium through congenital atrial septal defect, and flow into the cerebral artery leading to the cerebral ischemia infarction. The hyperbaric oxygen treatment initiates as early as possible. Hyperbaric oxygen can help the patients to be consciousness. In our case, we find hyperbaric oxygen treatment playing an important role in recovery. Besides, it speeds up the dissolution of air emboli by applying $100 \%$ oxygen inhalation..$^{14}$ The symptoms are improving slowly at first, but the patient shows a significant improvement of neurological dysfunction after one month.

Table I Studies of cerebral air embolism after central venous catheter removal

\begin{tabular}{|l|l|l|l|l|l|l|l|}
\hline Study/Year & Age/Sex & Site & Symptoms & CT/MRI & PFO & Diagnosis & Outcomes \\
\hline $\begin{array}{l}\text { Brockmeyer } \\
\text { et al. }\end{array}$ & 57/F & RIJV & $\begin{array}{l}\text { Dizziness, difficulty } \\
\text { breathing, seizure }\end{array}$ & $\begin{array}{l}\text { Cerebral air } \\
\text { embolism }\end{array}$ & Yes & PCAE & $\begin{array}{l}\text { Left lower extremity } \\
\text { weakness and } \\
\text { profoundly weak in the } \\
\text { left upper extremity }\end{array}$ \\
\hline $\begin{array}{l}\text { Hsiung and } \\
\text { Swanson] }\end{array}$ & $43 / \mathrm{M}$ & RIJV & $\begin{array}{l}\text { Short of breath, } \\
\text { somnolent and left } \\
\text { hemiparesis }\end{array}$ & $\begin{array}{l}\text { Multiple embolic } \\
\text { infarcts }\end{array}$ & Yes & PCAE & $\begin{array}{l}\text { Walk on his own after } \\
\text { I2 weeks, but had } \\
\text { residual problems with } \\
\text { left hemiparesis }\end{array}$ \\
\hline Oyama et al.5 & $49 / \mathrm{F}$ & RIJV & $\begin{array}{l}\text { Unconscious \& } \\
\text { respiratory distress, } \\
\text { mild numbness in limbs }\end{array}$ & $\begin{array}{l}\text { Air bubbles in } \\
\text { Subarachnoid } \\
\text { vessels }\end{array}$ & Yes & PCAE & $\begin{array}{l}\text { Neurologic deficits had } \\
\text { cleared completely }\end{array}$ \\
\hline lerssel et al. ${ }^{6}$ & $70 / M$ & LSV & $\begin{array}{l}\text { Lost consciousness, a } \\
\text { paralysis of left arm } \\
\text { and leg }\end{array}$ & $\begin{array}{l}\text { Air in the sinus } \\
\text { cavernous bilaterally }\end{array}$ & No & CVAE & $\begin{array}{l}\text { Recovered within I } \\
\text { hour }\end{array}$ \\
\hline Yamanaka et al. & $89 / F$ & RIJV & $\begin{array}{l}\text { Level of consciousness } \\
\text { worsened a few } \\
\text { minutes }\end{array}$ & $\begin{array}{l}\text { Air bubbles in } \\
\text { bilateral cavernous } \\
\text { sinuses }\end{array}$ & No & CVAE & $\begin{array}{l}\text { Air bubbles disappear } \\
\text { after I0 hours }\end{array}$ \\
\hline
\end{tabular}

RIJV, Right Internal Jugular Vein; LSV, Left Subclavian Vein; PFO, Patent Foramen Ovale; PCAE, Paradoxical Cerebral Air Embolism; CVAE, Cerebral Venous Air Embolism

The cerebral air embolism followed by central catheter removal should be concerned. The patient is in supine or head down. The patient is instructed to hold the breath at the end of inspiratory. While the catheter pulling out, the gauze pressing is no less than 5 minutes.
The skin exit site which the central venous catheter left would be covered or sealed by Vaseline gauzes or with antibiotic ointments. In order to prevent the outside air entering into the intravenous through the residual track, the airtight adhesive tapes should be used. All 
potential risks such as laughing, coughing as well as turning to upright position which change the pressure of intrathoracic might be avoided. It is recommended that the patient be in supine position for at least half an hour after central venous catheter removal. ${ }^{9}$ The symptoms presenting after the central venous catheter removal, although it is rare, should we consider the complication of cerebral air embolism. Prevention is rather important to decrease morbidity and mortality.

\section{Conclusion}

It is important to prevent cerebral air embolism when removing the central venous catheter. The approaches are as follows: asking patient in supine position, instructing patient breath holding, applying Vaseline gauzes or antibiotic ointments and covering the exit site with airtight tapes.

\section{Acknowledgments}

None.

\section{Conflicts of Interstet}

None.

\section{References}

1. McGee DC, Gould MK. Preventing complication of central venous catheterization. $N$ Engl J Med. 2003;348(12):1123-1133.

2. Muth CM, ShankES. Gas embolism. NEnglJMed.2010;342(7):476-482.

3. Brockmeyer J, Simon T, Seery J, et al. Cerebral air embolism following removal of central venous catheter. Mil Med.174(8):878-881.

4. Hsiung GY, Swanson PD . Cerebral air embolism after central venous catheter removal. Neurology. 2000;55(7):1063-1064.
5. Oyama N, Sakaguchi M, Kitagawa K. Air tract in the thrombus: paradoxical cerebral air embolism through a residual catheter track. $J$ Stroke Cerebrovasc Dis. 2012;21(8): 905.

6. Van Ierssel S, Specenier P, Baar I, et al. Acute hemiplegia caused by a retrograde cerebral venous air embolism after central venous catheter removal: an illustrative case. Acta Clin Belg. 2010;65(1): 51-53.

7. Yamanaka T, Miyazaki Y, Sato M. Retrograde cavernous sinus air embolism after central venous catheter removal. No Shinkei Geka 2012;40(11):991-995.

8. Mennim P, Coyle CF, Taylor JD. Venous air embolism associated with removal of central venous catheter. BMJ. 1992;305(6846): 171-172.

9. Peter DA, Saxman C. Preventing air embolism when removing CVCs: an evidence--based approach to changing practice. Medsurg Nurs. 12(4): 223-228.

10. Pronovost PJ, Wu AW, Sexton JB. Acute decompensation after removing a central line: practical approaches to increasing safety in the intensive care unit. Ann Intern Med. 140(12):1025-1033.

11. Fisher DC, Fisher EA, Budd JH, et al. The incidence of patent foramen ovale in 1,000 consecutive patients. Chest 107(6): 1504-1509.

12. Ponsky JL, Pories WJ. Paradoxical cerebral air embolism. N Eng J Med. 1971;284(17):985.

13. Black M, Calvin J, Chan KJ, et al. Paradoxic air embolism in the absence of an intracardiac defect. Chest.1991;99(3):754-755

14. Heckmann JG, Lang CJ. Neurologic manifestations of cerebral air embolism as a complication of central venous catheterization. Crit Care Med. 2000;28(5):1621-1625. 